\title{
Innovations for Smoke Management in Passenger Trains
}

\author{
Mariano Lázaro $^{* 1}$, David Lázaro ${ }^{1}$, Edurne Cortabarria ${ }^{2}$ and Daniel Alvear ${ }^{1}$ \\ ${ }^{1}$ University of Cantabria, Santander, Spain \\ ${ }^{2}$ Construcciones y Auxiliar de Ferrocarriles (CAF), Beasain, Spain
}

\begin{abstract}
Spanish manufacturer CAF developed an innovative alternative for compartmentation, based on a smoke extraction system, to guarantee safe conditions during evacuation processes in a passenger unit. To demonstrate its performance in a train unit, a real scale experimental programme, supported by the application of fire computer modelling, was applied in a new CAF's rolling stock. The new smoke exhaust system aims to extract the smoke generated during a fire in the passenger area by exhaust fans of the HVAC system, allowing the ingress of fresh exterior air in the lower part of the rear ends of the car. These key elements create an air flow that evacuates the smoke to prevent people from being exposed to it. Full scale fire tests were developed in the train unit following the Australian standard SA4391. A fire of $140 \mathrm{~kW}$ was used and the smoke was generated by a clean smoke machine. Measurement points included 6 thermocouples trees, 10 gas flow velocity probes and 2 GoPro HD video cameras (for the estimation of the visibility). The system performance was successful with the tenability criteria, since the value of visibility at the non-fire car was greater than $30 \mathrm{~m}$ and the temperature was lower than $30{ }^{\circ} \mathrm{C}$ during all the test at a height of $1.7 \mathrm{~m}$ above the floor. Experimental results were used to validate the computational model. The computational model results show a good accuracy compared with the tests.
\end{abstract}

Keywords: Fire Modelling; Smoke management; Train; Fire Safety; Real Scale Fire Tests.

\section{Introduction}

During the last decades, several major fire incidents have occurred in railway transport systems, causing hundreds of deaths ${ }^{1}$. For that reason, several research initiatives, as research done by $\mathrm{NIST}^{2}$, FIRESTARR ${ }^{3}$ or TRANSFEU $^{4}$, have been carried out to analyse fire safety in railway transport systems. These research programmes involved small-, medium- and real-scale fire tests, but also, the combination of small-scale and full-scale test has been used to analyse the fire behaviour of interior materials of highspeed trains ${ }^{5}$. Additionally, the influence of the ignition source location in different compartment sizes and configurations has been analysed by Prof. Fleischmann ${ }^{6}$, and it has been found that these parameters significantly influence fire development.

Additionally to the experimental tests, fire computer models have been used to analyse fire safety conditions in trains. CFAST fire model was used by NIST to predict the fire

\footnotetext{
* Corresponding author:

Mariano Lázaro, University of Cantabria, Avda. De Los Castros, s/n, 39005 Santander, Cantabria, Spain.

Email: mariano.lazaro@unican.es
} 
hazards within a passenger rail $\mathrm{car}^{7}$. Comparison of times to untenable conditions for a range of fire sizes determined from experimental measurements with those calculated by the CFAST showed agreement that averaged approximately 13 percent. Another computational model as Fire Dynamic Simulator (FDS) has been also used to analyse the smoke movement in high speed passenger trains ${ }^{8}$.

Fire development in a train carriage was also investigated by numerical simulations ${ }^{9}$. They applied two methods to perform the simulations, i.e. the simple ignition model and the kinetic pyrolysis model. The model parameters were estimated and calibrated based on data obtained from ThermoGravimetric Analysis (TGA) tests and cone calorimeter tests. The use of computational fire modelling combined with the results provided by cone calorimeter experiments demonstrated important advantages over the traditional approaches in fire safety applied to passenger trains ${ }^{10}$.

Moreover, manufacturers, operators, regulatory entities, etc., have been working on new regulations and innovative measures that might well improve life safety in trains. Around the world, countries have defined their own standards, considering distinct requirements and methods for fire-testing railway products and systems. The European Standard EN $45545^{11}$ specifies the measures for fire protection of railway vehicles in $\mathrm{UE}$ and the methods for verifying these measures.

Part 3 of this standard states the requirements for barriers fire-resistance. Compartmentation of passenger cabin, considered in regulations, aims to avoid fire propagation inside the occupied areas. In this sense, 15 minutes of fire resistance is a common requirement in EU passenger trains ${ }^{12}$. However, on the one hand, it is highly unlikely to implement that measure due to the complex services and installations which need to pass fire barriers. On the other hand, the major challenge, which must be faced for fire life safety, is essentially related with early stages of the fire, when the main objective will be to avoid the affectation of passengers by toxic gases during the evacuation process to not affected areas of the train until the vehicle can reach a safety point.

Therefore, a suitable control of smoke manifestations may well fulfil this technical ambition. According this challenge, the Spanish manufacturer CAF developed an innovative alternative for compartmentation, based on a smoke extraction system, to guarantee safe conditions during evacuation processes in a passenger unit. A real scale experimental programme, supported by the application of fire computer modelling, was carried out in a new CAF's two-car rolling stock to assess its performances.

This paper includes a description of the real-scale tests ${ }^{13}$ and the main results of the real-scale tests and computational modelling activities.

\section{Full Scale Tests}

\subsection{Train geometry and smoke exhaust system}

For the study, it was selected a real train unit of two coaches with an intercommunication gangway, specifically, a new CAF's DMU two-car rolling stock. This configuration might be also considered a worst scenario due to the limited available volume for smoke propagation. The train included all the real materials and 
furniture (pairs of seats on either side of the aisle, tables, luggage racks, ceiling and wall panels, universal toilet, cabinets, etc.) and the new exhaust system. Figure 1 shows the layout and dimensions of the train used.

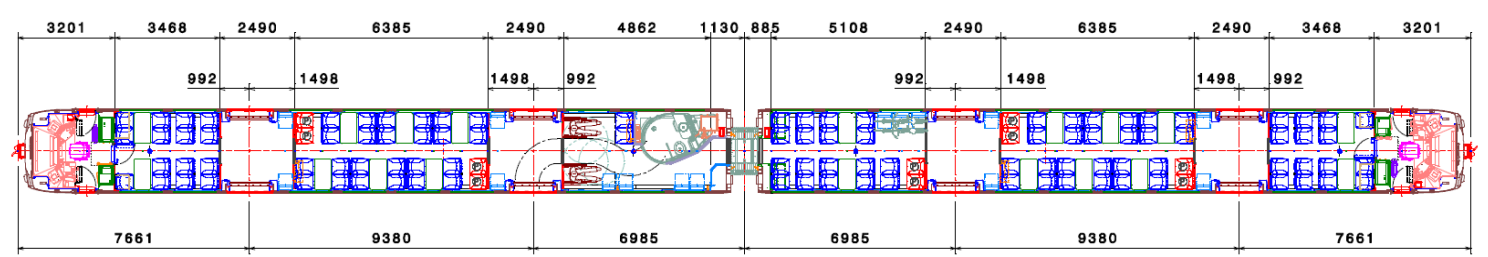

Figure 1. Layout of the train unit.

The new smoke exhaust system aims to extract the smoke generated during a fire in the passenger area, allowing the ingress of fresh exterior air in the lower part of the rear ends. These key elements are located in the body ends of the car (Figure 2), creating an air flow that evacuates the smoke generated by the fire to prevent people from coming into contact with smoke. The smoke exhaust system is activated by a smoke detection system available in the train. The exhaust fans that are used for the smoke extraction will blow a flow rate of $1500 \mathrm{~m}^{3} / \mathrm{h}$.

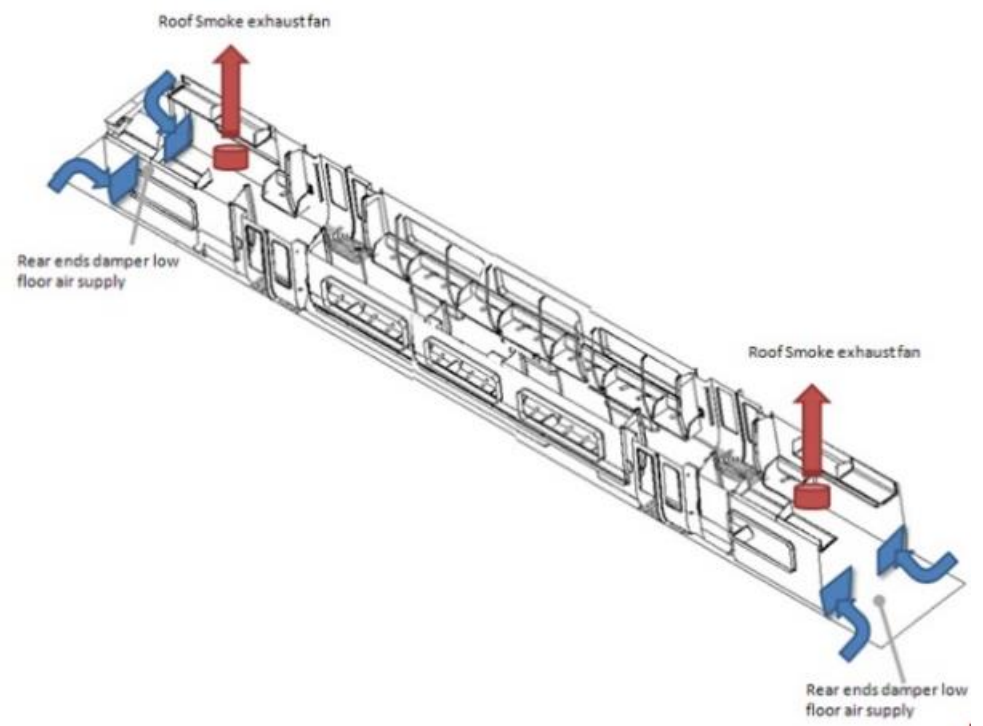

Figure 2. Key elements of the Smoke Exhaust System.

Additionally, all the doors of one side were opened at 5 minutes of the start of the fire, representing the arrival time to a station or evacuation platform, when the evacuation begins.

\subsection{Methodology}

To begin with, a data collection campaign was carried out to understand the actual features of the new exhaust system and to obtain gas flow velocities in the critical areas. This information was used to implement input data for the simulations, which facilitate the design of the real scale experiments. 24 simulations were performed by using the fire computer model Fire Dynamics Simulator (FDS) ${ }^{14}$. These simulations enable us to adjust the parameters of the new exhaust system and to define the critical scenarios to 
perform the real scale test. For reasons of space, these previous works will not be included in this paper.

For the development of the tests, it was followed the Australian standard AS 4391 'Smoke management systems - hot smoke test' ${ }^{15}$. This method has the endorsement of hundreds of tests and multiple works on its use for the verification of installed safety solutions and for obtaining input data to compare with computer models ${ }^{16-17}$. The standard indicates a combination of a tray with a liquid fuel (methylated spirit) with a smoke machine for the generation of clean smoke. In this way, a plume of hot gases is obtained through the tray, but without the generation of toxic smoke due to the characteristics of that fuel. The required amount of smoke can be set in the smoke machine. Note that the fuel considered is Denatured Industrial Grade Methylated Spirit (Grade 95), which is cost effective and produces clean combustion products, having a low radiation output.

It is interesting to comment that hot smoke tests have several limitations ${ }^{15-17}$. The main constrains ${ }^{16}$ are related to the maximum temperatures reached in the physical scenario to avoid damage. Therefore, in most cases the temperatures are much lower than expected values by a real fire. Additionally, since clean pool fires are used to create buoyancy, the fire growth tends to be faster than typical fire development.

Fire tests of onboard materials and products (described in Standards EN 45545-2 and EN45545-3) and design requirements (described in Standards EN 45545-4 and EN45545-7) are based on five different types of ignition models (EN 45545-1 ${ }^{18}$ ). In the study, the fire size was a requirement defined by the railway operator which established this ignition model 5 as target design fire. This model 5 describes the worst scenario, such as baggage and arson fires.

For experimental purposes, a pool fire of $140 \mathrm{~kW}$ was considered, provided by a tray of size A2, which is expected to generate a fire curve with a first growing stage during approximately $3 \mathrm{~min}$, a steady state burning for $10 \mathrm{~min}$ and $3 \mathrm{~min}$ for the fire decayment. The duration of the tests was adjusted to 11.5 min to obtain the same fire severity in terms of total energy released as the curve of the ignition model 5 (see Figure $3)$.

Additionally, the amount of smoke generated was given by the clean smoke machine. The clean smoke machine allows to modifying the amount of smoke generated and, with that, the visibility in the compartment. In our case, we used $168 \mathrm{mg} / \mathrm{s}$, equivalent to $20 \mathrm{psi}$ in the input pressure of the smoke machine to get a visibility between $1.3 \mathrm{~m}$ and $2.5 \mathrm{~m}$ in $5 \mathrm{~min}$ in the volume of the train. Additionally, we performed several simulations to calibrate the model and getting the same visibility in 5 min without the system. 


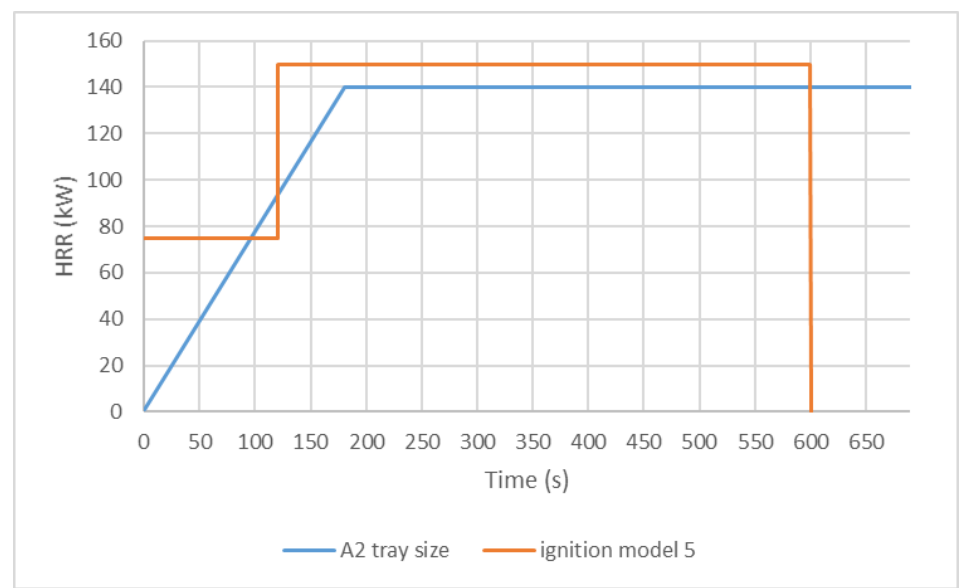

Figure 3. Comparison between the HRR curve produced with a tray of size A2 and the curve of the ignition model 5.

During the fire experiments, the smoke movement was analysed by monitoring different parameters, such as temperature, visibility and gas flow velocities. Although AS 4391 states that "It is not intended as a means of establishing smoke obscuration levels or system integrity under real fire conditions", depending the scenario of application of the AS 4391, results could be closer to real fire conditions. As Webb [16] concludes, in certain kind of scenarios the application of the AS 4391 present differences between the hot smoke test and the real fires are related with the temperatures in the ceiling jet above the fire, which in some scenarios as the studied by Webb, must be limited to less than $55^{\circ} \mathrm{C}$ to ensure sprinklers are not activated. Nevertheless, in the scenario studied in the paper, it can be seen temperatures over $100{ }^{\circ} \mathrm{C}$ in the hot smoke layer. The other limitation which define Webb is related with the fire growth, which is close to instantaneous in the hot smoke tests, nevertheless, this is in the side of safety. Taking into account these points, the use of the hot smoke test in our scenario may well estimate both the interface of the hot smoke layer and the impact of the fire manifestations on the sustainability of users during the emergency actions.

The criteria used for analyses the performance of the system were the following ones:

- the visibility shall be not less than 6 meters at a height of $1.7 \mathrm{~m}$ above the car floor level measured at the first vestibule of the non-fire effected car,

- the temperature shall not be greater than $60^{\circ} \mathrm{C}$ at a height of $1.7 \mathrm{~m}$ above the car floor level measured at the first vestibule of the non-fire effected car.

\subsection{Fire scenario}

3 non-destructive tests were carried out to study the response of the innovative system in case of fire on-board. The fire was located in the vestibule closer to the intercommunication gangway and near the PRM WC area. Additionally, it is necessary to indicate that all elements near the source of ignition (walls, doors, roof, floor, furniture and systems such as cameras, television screens, etc.) were protected with fireproof materials, as we can see in the Figure 4a. Figure $4 \mathrm{~b}$ displays the location of the ignition source in a plane. 


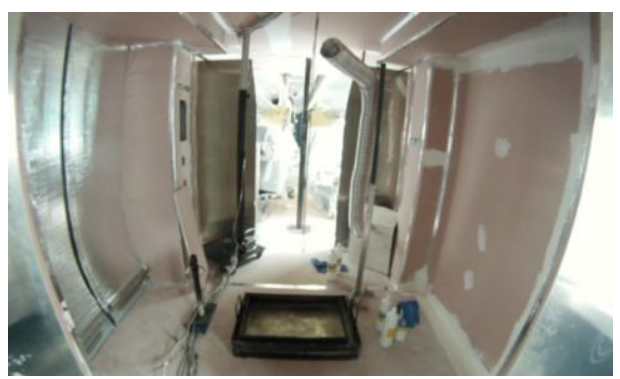

(a)

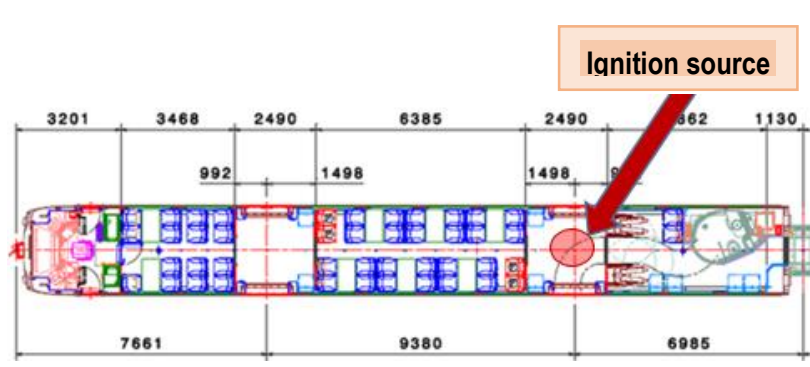

(b)

Figure 4. (a) View of the train protection in the elements close to the ignition source, (b) Localization of fire scenario.

For the test, both the fire tray and the smoke machine was located at floor level.

\subsection{Instrumentation}

During the fire tests, different instruments were used for measuring several parameters (Figure 5). Measurement points included 5 thermocouples trees (10 thermocouples each tree), 1 thermocouples tree ( 8 thermocouples) in the vertical of the ignition source, 10 gas flow velocity probes and $3 \mathrm{HD}$ video cameras (for the estimation of the visibility).

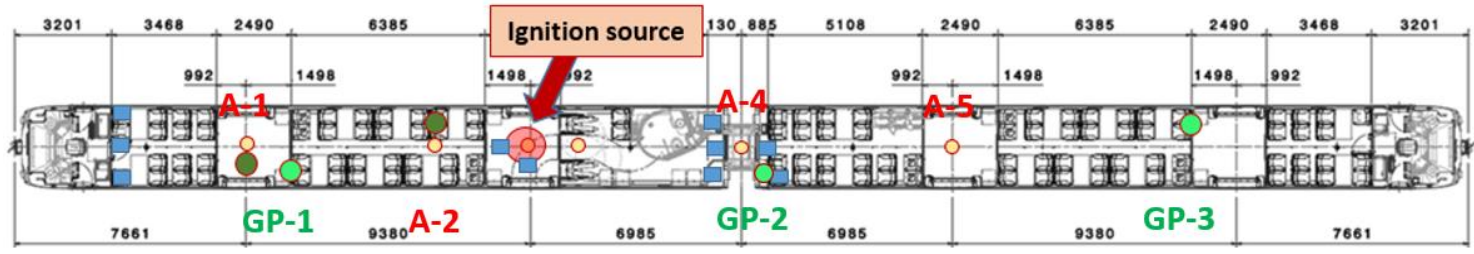

Figure 5. View of the setup of the real fire tests: ignition source, thermocouples trees $(\circ)$, velocity probes $(\square)$, GoPro HD video cameras (०) and video cameras (๑).

All gas-phase thermocouples were type $\mathrm{K}$ with a stainless steel sheath and mineral fibre insulation of diameter $1.5 \mathrm{~mm}$ (Reference: TC Direct 12-K-10000-118-1.5-2I-3P2L1MTR C40KX). The thermocouples were deemed to be accurate between -200 and $1250{ }^{\circ} \mathrm{C}$. The response time of thermocouples is $0.3 \mathrm{~s}$, and their tolerance is in accordance with IEC 584.2 , class $2\left( \pm 2.5^{\circ} \mathrm{C}\right.$ between $-40{ }^{\circ} \mathrm{C}$ and $333{ }^{\circ} \mathrm{C}$, and $\pm 0.0075 \cdot|\mathrm{t}|$ between $333^{\circ} \mathrm{C}$ and $\left.1200{ }^{\circ} \mathrm{C}\right)^{19}$.

3 (three) thermocouples trees were located in the car with the ignition source, 1 (one) in the gangway and 1 (one) more in the adjacent coach. 10 (ten) thermocouples were attached to each tree at different heights. The upper thermocouple was placed $2.1 \mathrm{~m}$ from the floor, and the rest of them were placed with a separation of $0.2 \mathrm{~m}$. Additionally, 1 (one) tree (with eight thermocouples) was located in the vertical of the fire tray.

For the measurement of the gas flow velocity, thermal flow sensors (Reference: KIMO CTV 100) were used. Kimo's CTV 100 measures temperature and air velocity from 0 to $30 \mathrm{~m} / \mathrm{s}$ and from 0 to $50{ }^{\circ} \mathrm{C}$. For the measurement of air velocity, the accuracy is $\pm 3 \%$ of reading $\pm 0.3 \mathrm{~m} / \mathrm{s}$, the response time is $1 / \mathrm{e}(63 \%) 2 \mathrm{~s}$, and the resolution is $0.1 \mathrm{~m} / \mathrm{s} .3$ (three) probes were placed to measure the velocity of the gases extracted and 5 (five) probes to measure the velocity of air that enters in the train. 2 (two) additional probes 
were placed near the ignition source to control the ventilation conditions during the tests.

For the estimation of the visibility in both cars and in the gangway, 3 (three) GoPro HD video cameras were placed at a height of $1.7 \mathrm{~m}$. These video cameras pointed to an element that was used as reference. Finally, the results were analyzed with the Matlab software and an approximate method was used which, through the light intensity of the pixel, allows us to estimate the level of visibility through its inverse (coefficient of extinction) according to the expression ${ }^{20-21}$.

$$
K_{e}=-\frac{1}{L} \ln \left(\frac{I_{\text {in }}}{I_{\text {out }}}\right)
$$

where $K_{e}$ is the extinction coefficient $\left(\mathrm{m}^{-1}\right), L$ is the distance between the camera and the reference $(\mathrm{m})$, and $I$ is the light intensity.

Finally, 2 (two) video cameras were placed to record and control in real time all the tests (ignition source-smoke machine, general view, etc.).

\subsection{Full scale tests results}

In this section, the results of one of the three full-scale fire tests are presented. The results of the other two tests were similar to this one.

\subsubsection{Temperature results}

Figure 6 shows the results of the thermocouples at $1.7 \mathrm{~m}$ height on thermocouple trees placed inside the car where the fire source was placed and inside the adjacent car.

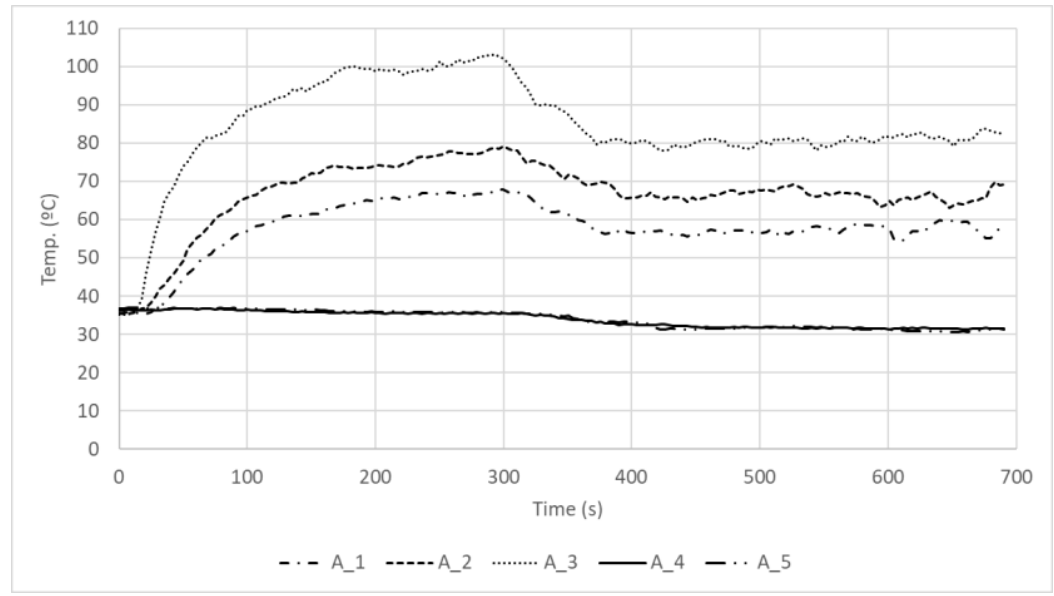

Figure 6. Results of the thermocouples at $1.7 \mathrm{~m}$ height on the thermocouple trees placed inside the car where the ignition source was located (A_1, A_2 and A_3) and inside the adjacent car (A_4 and A_5).

We can see that there is no affectation inside the adjacent car, but inside the car where the ignition source was located we can find a temperature higher than $100{ }^{\circ} \mathrm{C}$ at a height of $1.7 \mathrm{~m}$. 
Additionally, Figure 7 shows the results of the thermocouple tree placed in the vertical fire plume.

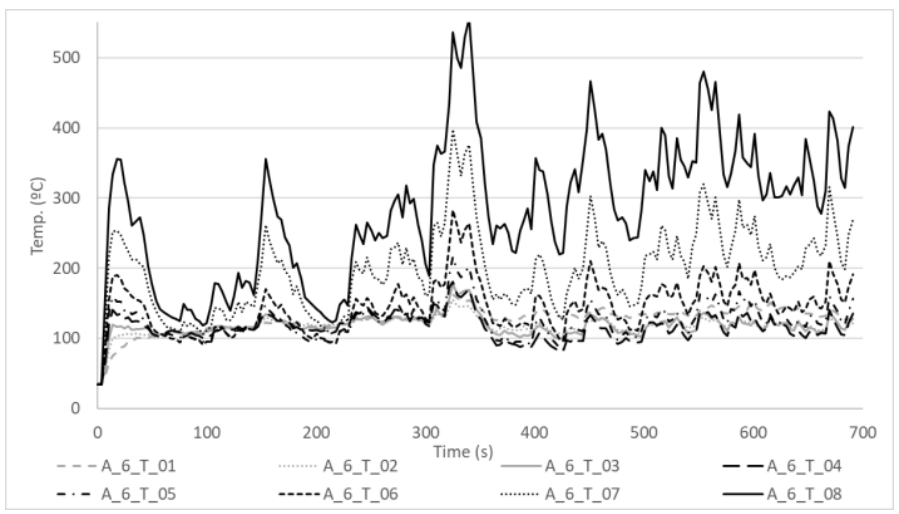

Figure 7. Results of the thermocouple trees placed in the vertical of the ignition source.

Finally, Table 1 includes a summary of the maximum temperature obtained in each thermocouple tree.

Table 1. Maximum temperature in the thermocouples trees.

\begin{tabular}{lcccccc}
\hline & $\mathrm{A}-1$ & $\mathrm{~A}-2$ & $\mathrm{~A}-3$ & $\mathrm{~A}-4$ & $\mathrm{~A}-5$ & $\begin{array}{c}\mathrm{A}-6 \\
\text { (Ignition } \\
\text { source) }\end{array}$ \\
\hline $\begin{array}{l}\text { Maximum temp. } \\
\text { Time to peak }\end{array}$ & $78^{\circ} \mathrm{C}$ & $93^{\circ} \mathrm{C}$ & $112^{\circ} \mathrm{C}$ & $47^{\circ} \mathrm{C}$ & $38^{\circ} \mathrm{C}$ & $557^{\circ} \mathrm{C}$ \\
\hline
\end{tabular}

We can see maximum temperatures inside the car where the fire source was placed between $78{ }^{\circ} \mathrm{C}$ and $112{ }^{\circ} \mathrm{C}$, and this maximum value was reached about the $300 \mathrm{~s}$ (moment when the doors of one of the sides were opened). Inside the adjacent car, the maximum temperatures were lower than $50{ }^{\circ} \mathrm{C}$ and the maximum value was reached in the moments close to the start of operation of the exhaust system.

\subsubsection{Visibility results}

Figure 8 shows a series of photographs taken at 1 min., 5 min. (opening of the doors) and $10 \mathrm{~min}$. from the start of the test, by the GoPro cameras located according to Figure 5 . 


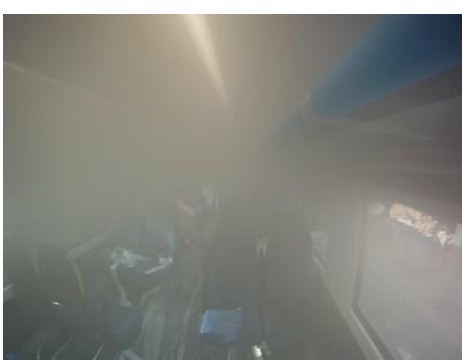

a1) GP-1 at $1 \mathrm{~min}$.

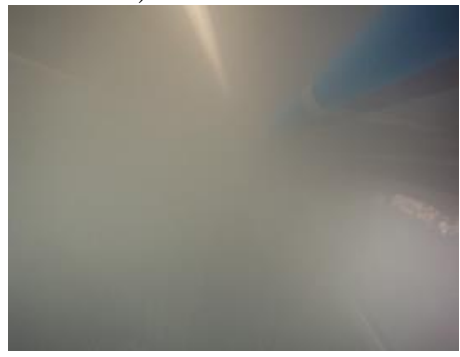

a1) GP-1 at $5 \mathrm{~min}$.

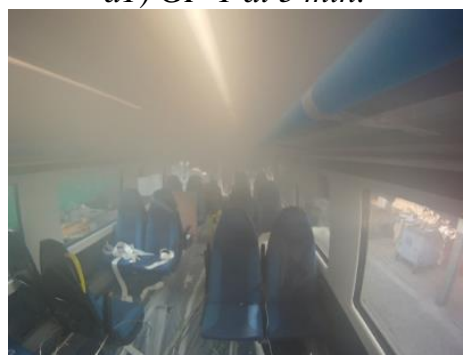

a2) GP-1 at $10 \mathrm{~min}$.

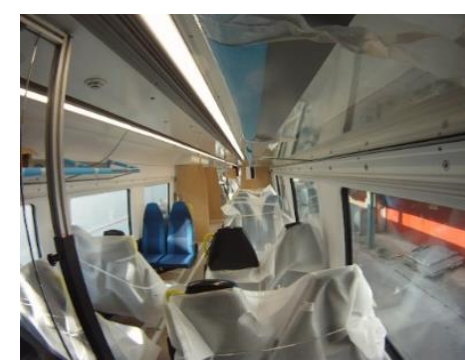

b1) GP-2 at $1 \mathrm{~min}$

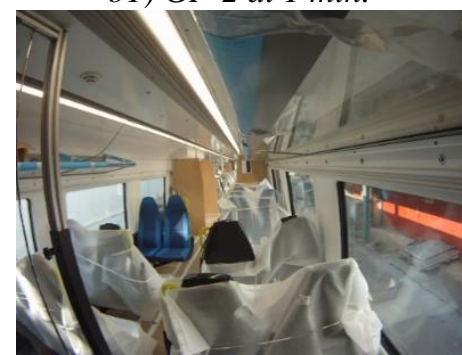

b1) GP-2 at $5 \mathrm{~min}$.

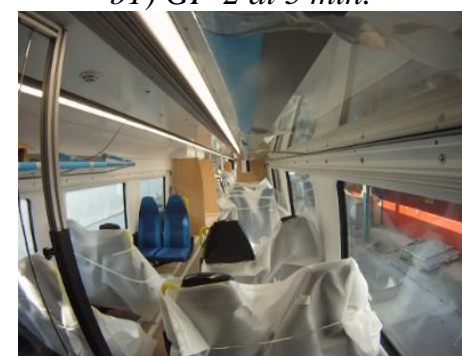

b2) GP-2 at $10 \mathrm{~min}$.

Figure 8. View of GoPro HD video cameras in positions: a) GP-1 and b) GP-2.

We can see that only in the camera located in the car in which the fire source was placed (GP-1), smoke appeared and might reduce the visibility of the occupants.

Additionally, Figure 9 shows the estimated results of visibility in each of the points previously indicated (GP-1, GP-2 and GP-3).

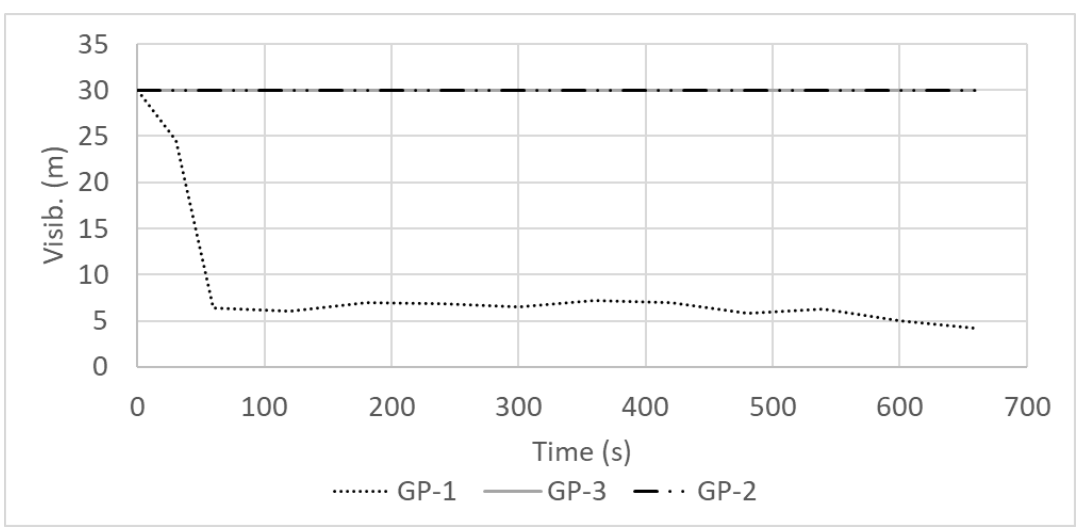

Figure 9. Curve of the estimated results of visibility at $1.7 \mathrm{~m}$ height. (Note: The results of GP-2 and GP-3 are superimposed).

\section{Numerical Simulations}


The fire model 'Fire Dynamics Simulator (FDS)', version 6.6.0 ${ }^{14}$ was used. This model has been developed by the Building and Fire Research Laboratory of the National Institute of Standards and Technology - NIST (USA). FDS is a Computational Fluid Dynamics (CFD) model, designed specifically for fire simulations. FDS solves numerically a form of the Navier-Stokes equations, which is appropriate for low-speed, thermally-driven flows with an emphasis on smoke and heat transport from fires.

The computational domain that represented the scenario geometry was divided into cubic cells of $0.1 \mathrm{~m}$ length. This resulted the division of the model in a total of 267960 cells. The computational domain has a length of $42 \mathrm{~m}$, a width of $2.7 \mathrm{~m}$ and a height of $2.2 \mathrm{~m}$. At the beginning of the simulation, the air temperature inside of the car is $34{ }^{\circ} \mathrm{C}$, outside of the car is $24^{\circ} \mathrm{C}$ (same measured during the tests) and it is at atmospheric pressure. Figure 10 shows the representation of the train in FDS model.

For simulations involving buoyant plumes, a measure of how well the flow field is resolved is given by the non-dimensional expression $\left(D^{*} / \delta_{x}\right)$, where $D^{*}$ is a characteristic fire diameter and $\delta_{x}$ is the nominal size of a mesh cell ${ }^{14,22,23}$. $\left(D^{*} / \delta_{x}\right)$ can be also understood as the number of computational cells spanning the characteristic (not necessarily the physical) diameter of the fire. The more cells spanning the fire, the better the resolution of the calculation. It is highly recommended this coefficient to have a value between 4 (coarse mesh) and 16 (fine mesh) ${ }^{24,25}$. In this case, the grid size was selected to be $0.1 \mathrm{~m}$, because with a HRR of $140 \mathrm{~kW}$, the obtained coefficient value is 4.37 .

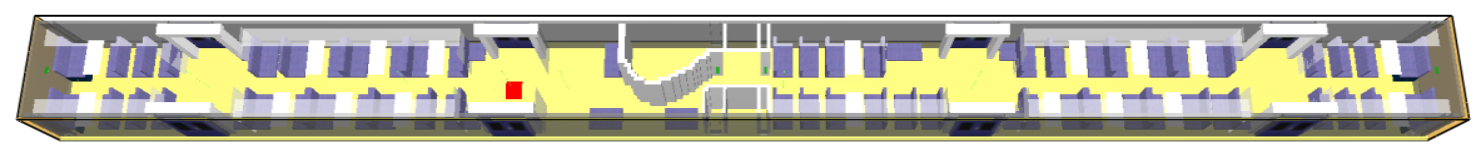

Figure 10. Representation of the train in FDS model.

The model included the characteristics of the extraction system, with two extraction points per car of $1500 \mathrm{~m}^{3} / \mathrm{h}$ and openings for the entry of air at the ends of the cars. Following the experimental procedure, after $30 \mathrm{~s}$, the VENTs that represent the extraction flow in the ceiling are activated and HOLEs are opened in the sides of the train for the entry of fresh air.

The ignition source was represented in the same position and with the same theoretical HRR curve previously indicated, and the measurement points were placed in order to compare the results with those obtained in the real tests.

A chemical reaction of combustion generated by Heptane $\left(\mathrm{C}_{7} \mathrm{H}_{16}\right)$ was used. A "simple chemistry" combustion model was used, with a value of the $\mathrm{CO}$ yield ${ }^{26}$ of $3.04 \mathrm{E}^{-5}$ and a value of the soot yield ${ }^{26}$ of 0.05 . All the materials used in the simulation were defined as inert.

Additionally, various longitudinal slices were also placed to analyse in a more global way the phenomena that were taking place inside the train.

As indicated throughout the paper, the computational simulation was carried out in order to assist in the development of the system and to validate the model against the 
results obtained in the tests. Starting from this point it is interesting to be able to carry out a sensitivity analysis for the train with the system in the future that allows analyzing the influence of certain key parameters of the ignition source on the results of the sustainability criteria. In the references there are similar sensitivity analysis works applied to other environments, e.g. the authors of this paper carried out an analysis for the case of nuclear power plants by varying 9 parameters of both the ignition source and the insulation of the walls ${ }^{27}$. Among other conclusions, the paper shows how a variation of the soot yield between 0.01 and 0.1 does not influence the maximum temperature of the room, nor does the variation of the $\mathrm{CO}$ yield influence the values of that maximum temperature. The greatest influence was obtained by varying the mass loss rate, the volumetric flow of incoming air and the radiative fraction. Wolfram et. al. ${ }^{28}$ took advantage of Dalmarnock's tests to perform a sensitivity analysis of different parameters and concluded that 'Simulations of the fire growth are significantly sensitive to the location of the HRR, fire area, material thermal properties, surface emissivity and flame radiative fraction, whereas the simulations are relatively insensitive to changes of the heat of combustion (while keeping the HRR constant), the soot yield and the heating from the smoke layer.'. In any case, as the soot yield is directly related to the smoke production, and in this case, one of the comparative parameters is visibility, a previous analysis was made to calibrate the amount of smoke generated by the smoke machine with the visibility data obtained in the FDS model. In the FDS verification and validation guides you can find more works similar to the previous ones.

Additionally, since this train is not expected to be operated in tunnel sections different external boundary conditions have not been considered, only the conditions found during the tests. As a new future work, it would be interesting to perform a sensitivity analysis changing the external boundary conditions in order to see the influence in the results.

\subsection{Results of model without the smoke exhaust system}

In order to have a point of comparison, a simulation was carried out in the first place without the inclusion of the smoke exhaust system in the train. Figure 11 and 12 show the results of this initial simulation.

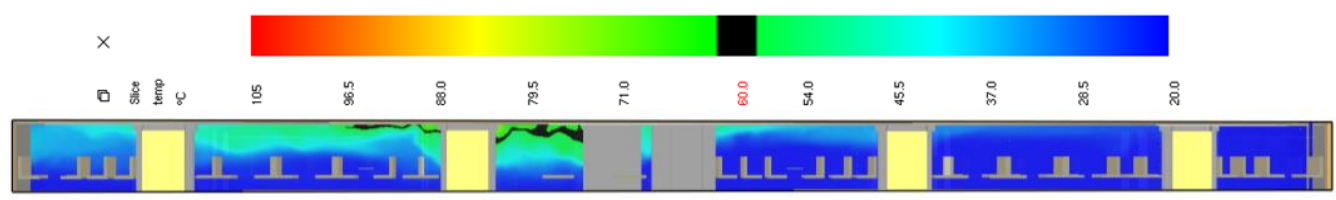

a) $100 \mathrm{~s}$.

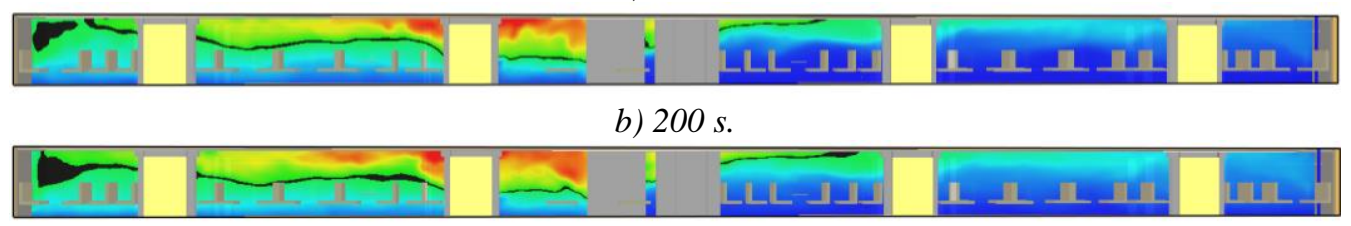

c) $300 \mathrm{~s}$.

Figure 11. Longitudinal slice of temperature by the centre of the train in FDS model. 


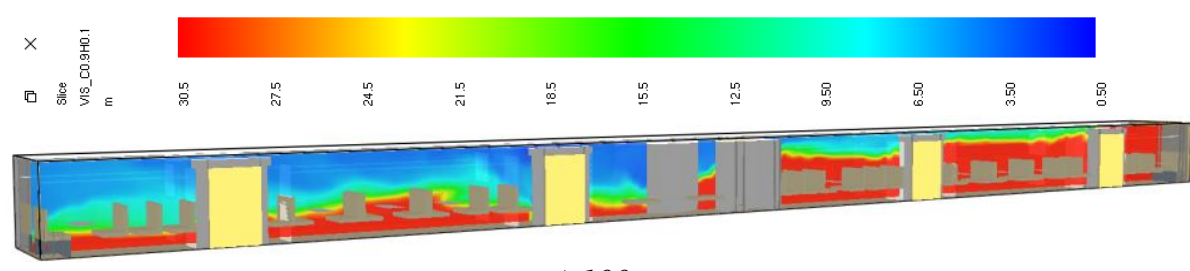

a) $100 \mathrm{~s}$.

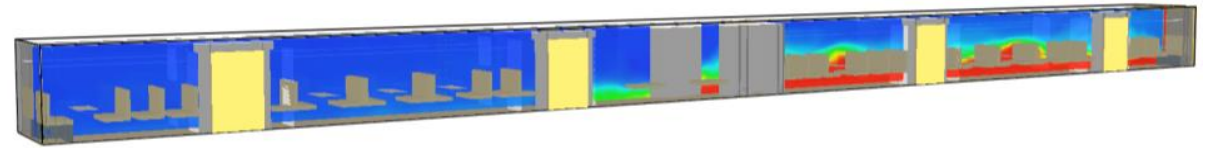

b) $200 \mathrm{~s}$.

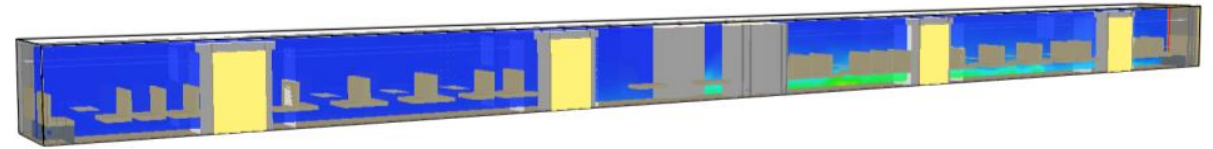

c) $300 \mathrm{~s}$

Figure 12. Longitudinal slice of visibility by the centre of the train in FDS model.

We can see affectation in both cars with temperatures greater than $60{ }^{\circ} \mathrm{C}$ in several areas. Additionally, there are manifestations of smoke in the adjacent car since the beginning, and at $300 \mathrm{~s}$ there are no visibility in all the train.

\subsection{Results of model with the smoke exhaust system}

Finally, several simulations were carried out with the inclusion of the smoke exhaust system in the train, and performing the adjustment of several parameters used as input data. Figure 13 and 14 show the results of one of the last simulations.

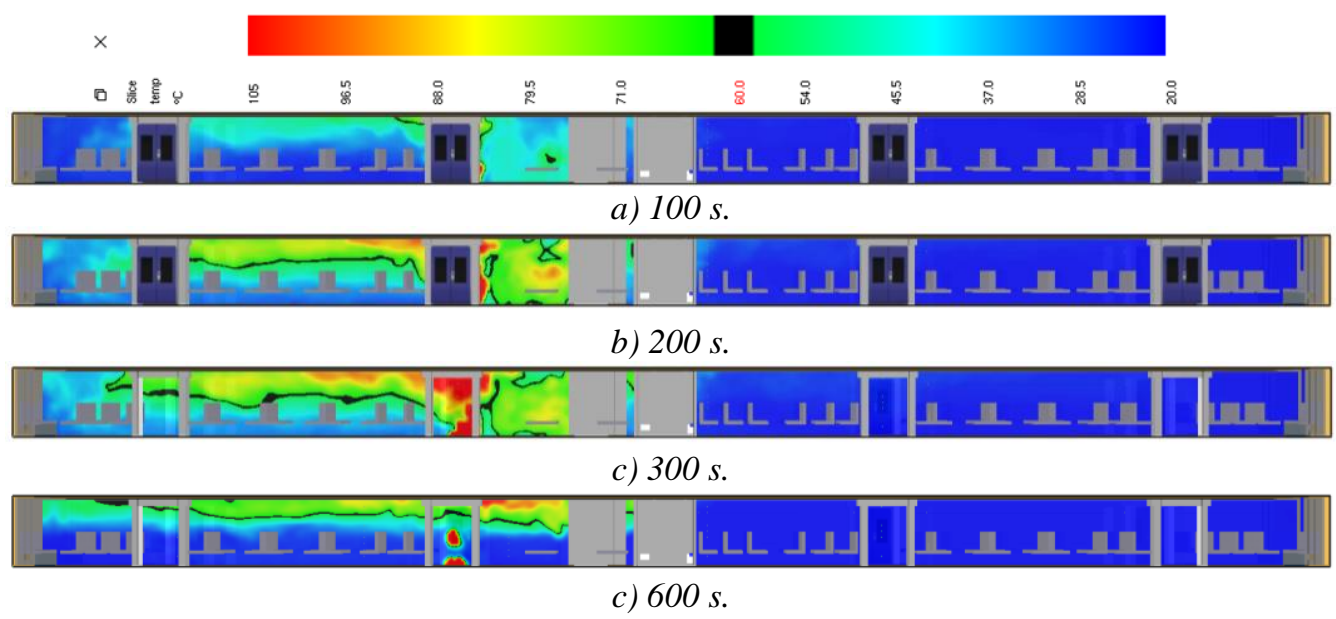

Figure 13. Longitudinal slice of temperature by the centre of the train in FDS model. 


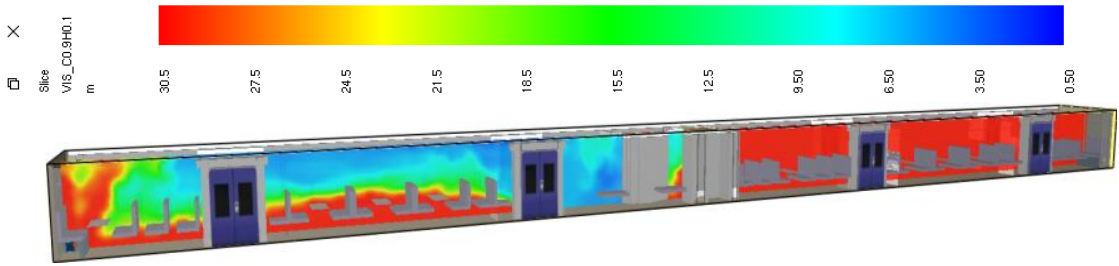

a) $100 \mathrm{~s}$.

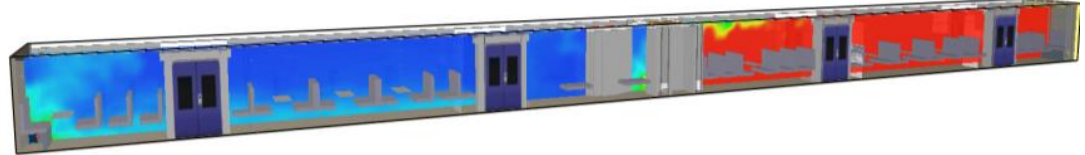

b) $200 \mathrm{~s}$.

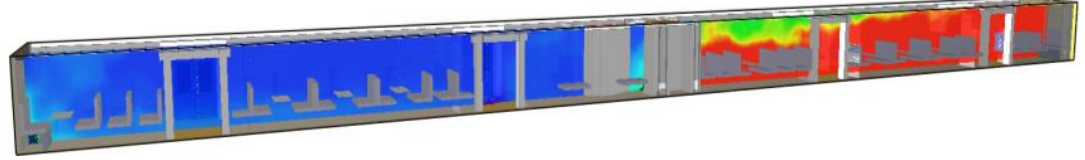

c) $300 \mathrm{~s}$.

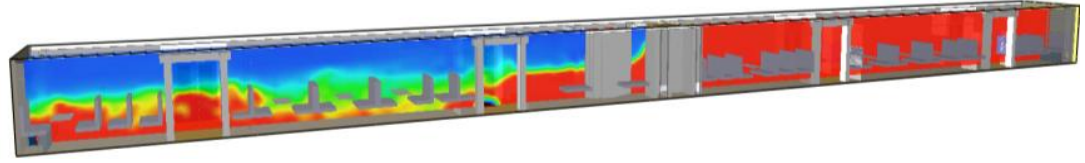

c) $600 \mathrm{~s}$.

Figure 14. Longitudinal slice of visibility by the centre of the train in FDS model.

In this case, we can see in the figures that the results of the simulation are successful and we can observe how the car adjacent is free of the manifestations of the fire.

\section{Discussion}

The expected objective was that visibility and temperature at the first vestibule of the non-fire car did not fail the tenability criteria. As it was possible to verify, the system performance was successful with the tenability criteria, since the value of visibility at the non-fire car was greater than $30 \mathrm{~m}$ and the temperature was lower than $30^{\circ} \mathrm{C}$ during all the test at a height of $1.7 \mathrm{~m}$ above the car floor level.

In this section, we are going to compare the results obtained by the model with and without the system, and the results of the model against those obtained during real-scale tests.

\subsection{Comparison of the model results without and with the smoke exhaust system}

Figure 15 shows a comparison between the results of the model that included the smoke exhaust system and the results of the model that did not include it. 


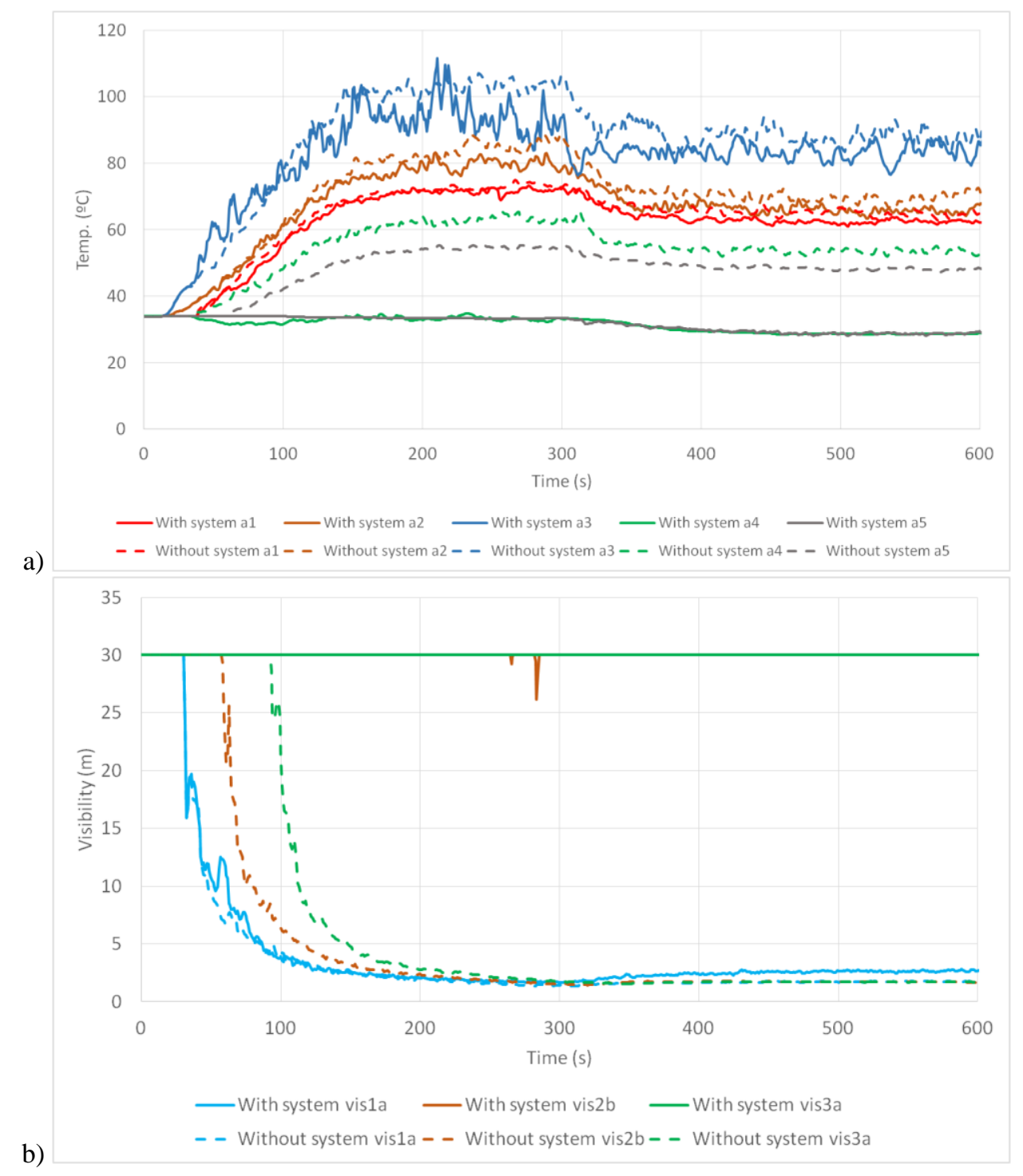

Figure 15. Comparison of temperature (a) and visibility (b) results without and with the system.

As can be seen in the previous graphs, the non-inclusion of the smoke extraction system makes the conditions in the adjacent car unsustainable. At the beginning of the car, the temperatures are higher than $60{ }^{\circ} \mathrm{C}$ and the visibility drops to values of approx. $2 \mathrm{~m}$. The opening of the doors improves the temperature conditions somewhat, with values a little higher than $50{ }^{\circ} \mathrm{C}$, but the visibility remains at values much lower than $4 \mathrm{~m}$.

\subsection{Comparison of the model and full-scale test results}

Figure 16 shows a comparison between the real full-scale test results and those obtained by the model. 


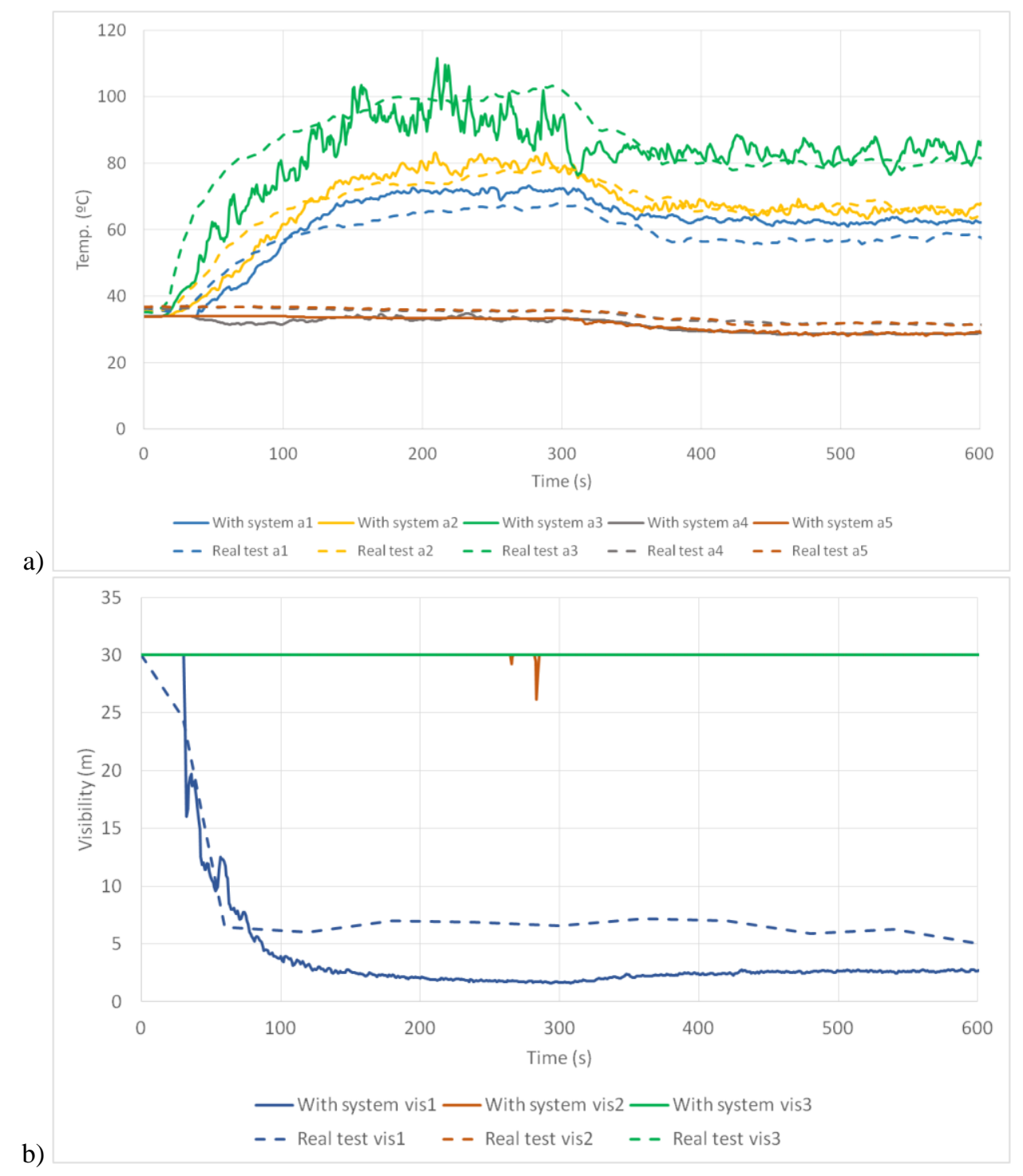

Figure 16. Comparison of temperature (a) and visibility (b) results for model with system and real test.

We can observe a good correlation in the results of the temperature at the height of 1.7 $\mathrm{m}$, but there is a variation of approx. $5 \mathrm{~m}$ in visibility results.

Additionally, Figure 17 shows the average temperature increase profiles registered at different heights in the thermocouple tree sited inside the train (Figure 5) for the full scale test and the FDS simulation. 


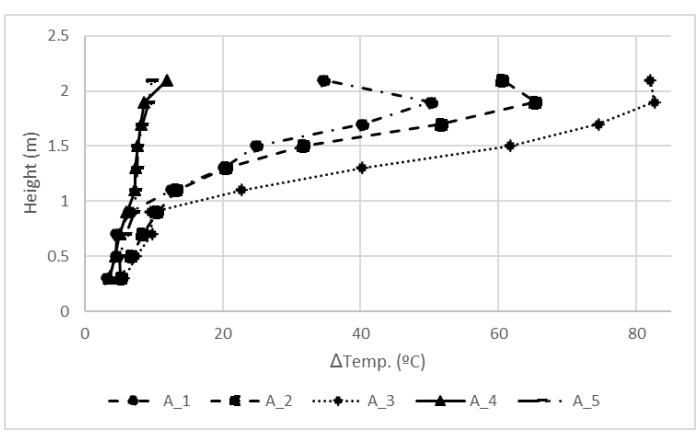

(a)

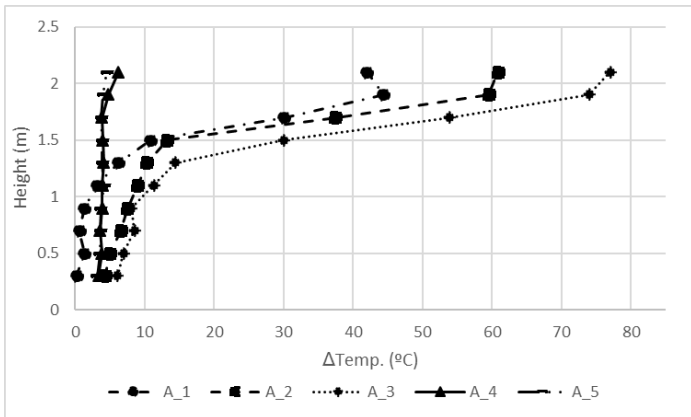

(c)

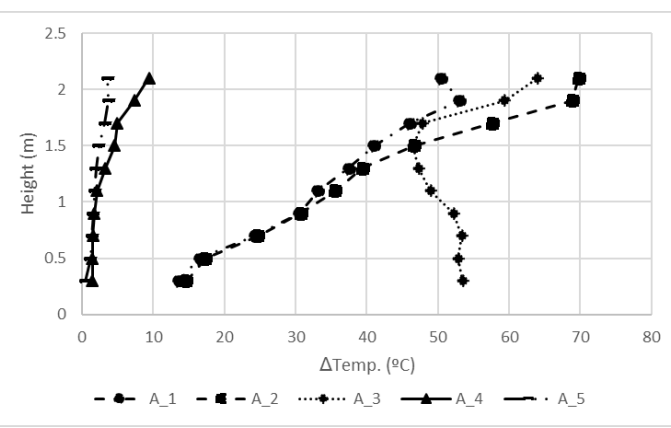

(b)

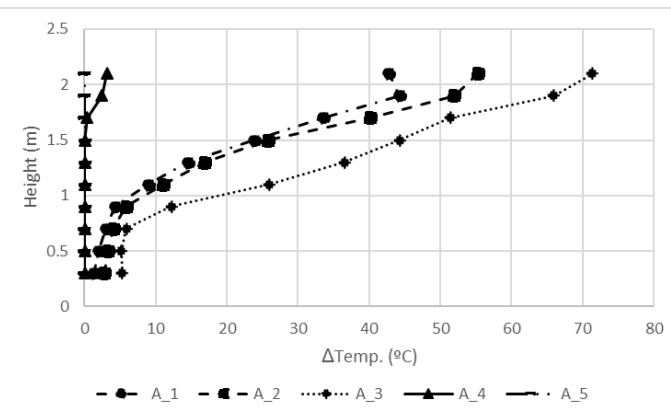

(d)

Figure 17. Temperature increase profiles results for full scale test and FDS model in all the thermocouples trees (A_1, A_2, A_3, A_4 and A_5). (a) Test at 300 s; (b) Simulation at $300 \mathrm{~s}$; (c) Test at $600 \mathrm{~s}$; (d) Simulation at $600 \mathrm{~s}$.

During the tests, it can be observed how temperature increases greater than $30{ }^{\circ} \mathrm{C}$ at heights higher than $1.5 \mathrm{~m}$, with the only exception of the tree closest to the ignition source (A_3) at the time instant of $300 \mathrm{~s}$, when this tree has a temperature increase of 60 ${ }^{\circ} \mathrm{C}$ at that height. However, the simulation provides higher increases at temperature of $30{ }^{\circ} \mathrm{C}$ for all points higher than $1 \mathrm{~m}$ and greater heating of the lower zones is observed. The A_3 tree simulation also reaches higher temperatures than the experimental test at lower heights, which may be caused by differences in the HRR definition.

These differences may be also related with the difficulty to represent the natural air intake through the grids of the exhaust system placed at the end of each car, and when the doors are opened this effect disappears, and the results between the test and the model approach.

Regarding the operation of the smoke exhaust system, it can be observed, both in the test and in the simulation, how the manifestations of the fire (mainly temperature and smoke) are confined in the car in which the fire is located, getting to keep the adjacent car in safe conditions. It can be observed that in the adjacent car there were maximum temperature increases below $10{ }^{\circ} \mathrm{C}$ at any height.

\section{Conclusions}

A non-destructive full-scale test was carried out, in order to assess the performance of an innovative smoke exhaust system in case of fire on-board of a two cars configuration train. The safety criteria were defined by visibility levels not less than 6 meters and temperature not greater than $60^{\circ} \mathrm{C}$, at a height of $1.7 \mathrm{~m}$ above the car floor level, 
measured at the first vestibule off the non-fire effected car. Moreover, experimental results were used to validate the computational model.

The system performance was successful with those tenability criteria, since the value of visibility at the non-fire car was greater than $30 \mathrm{~m}$ and the temperature was lower than $30{ }^{\circ} \mathrm{C}$ during all the test.

In most cases, the computational model results show a good accuracy compared with the tests. When the doors of the cars were closed and therefore the exit of the smoke and air intake was limited by the exhaust system, the results of the model were similar to the tests ones in the car where the ignition source was not located and in the upper thermocouples of the car where the ignition source was located. The simulation results in the lower thermocouples of the car where the ignition source was located were far from the results of the test. Once the doors were opened, the results were more accuracy in all points. Additionally, the simulation of the train and the system allowed to analyse the importance of the new system in maintaining sustainability conditions.

\section{References}

1. Beard, A.; Carvel, R. - "The Handbook of Tunnel Fire Safety", Thomas Telford Publishing, London, 2012.

2. Peacock, R.D. - Research Program about "Fire safety in passenger rail transportation", National Institute of Standards and Technology, NIST.

3. FIRESTARR Project CSNCF/01001 Contract SMT4-CT97-2164. Final Report 2001.

4. TRANSFEU Project. "A European step forward for engineering fire control"; A European Project supported through the 7th FP for Research and Technological Development.

5. Capote, J.A.; Jimenez, J.A.; Alvear, D.; Alvarez, J.; Abreu, O.; Lázaro, M. "Assessment of fire behaviour of high-speed trains' interior materials: small-scale and full-scale fire tests", Fire \& Materials, 38, 2014, p. 725-743.

6. Parkes, A.R.; Fleischmann, C.M. - "The impact of location and ventilation on pool fire in a compartment", Fire Safety Science, 8, 2005, p. 1289-1300.

7. Peacock, R.D.; Averill, J.D.; Madrzykowski, D.; Stroup, D.W.; Reneke, P.A.; Bukowski, R.W. - "Fire Safety of Passenger Trains; Phase III: Evaluation of Fire Hazard Analysis Using Full-Scale Passenger Rail Car Tests", NISTIR 6563, NIST, April 2004.

8. Capote, J.A.; Alvear, D.; Abreu, O.; Lázaro, M.; Blanco, H.; Saez, I.; López, I.; Arbildi, A. - "Physical scale and computational modeling of smoke movement in high speed passenger trains", International Congress Fire Computer Modeling, Santander, 2012.

9. Li, Y.Z. - "CFD modelling of fire development in metro carriages under different ventilation conditions", SP Report 2015:86, BRANDFORSK Project 400-131, 2015.

10. Capote, J.A.; Alvear, D.; Lazaro, M.; Espina, P. - "Heat release rate and computer fire modelling vs real-scale fire tests in passenger trains", Fire \& Materials, 32, 2008, 213-229.

11. European Standard. EN 45545:2013, 'Railway applications. Fire protection on railway vehicles. 2013 . 
12. European Standard. EN 45545-3:2013, 'Railway applications. Fire protection on railway vehicles. Part 3: Fire resistance requirements for fire barriers', 2013.

13. Lázaro, M.; Lázaro, D.; Cortabarria, E.; Alvear, D. - "Numerical Simulation and Full Scale Tests of a New Approach for Fire Management in Passenger Trains", Proceedings of the Ninth International Seminar on Fire and Explosion Hazards (ISFEH9), 2019.

14. McGrattan, K.; Hostikka, S.; et.al. - "Fire Dynamics Simulator. Technical Reference Guide. Volume 1: Mathematical Model", NIST Special Publication 1018-1, 6th edition, 2018.

15. Australian standard AS 4391-1999 Rec:2016, Smoke management systems - hot smoke test, 2016.

16. Webb, A. - "FDS modelling of hot smoke testing, cinema and airport concourse", Master Thesis, Worcester Polytechnic Institute, 2006.

17. Morgan, H.P.; De Smedt, J-C. - "Hot smoke tests: testing the design performance of smoke and heat ventilation systems and of impulse ventilation systems", International Journal on Engineering Performance-Based Fire Codes, Vol. 6, $\mathrm{n}^{\mathrm{o}}$, 2004, p. 7-18.

18. European Standard. EN 45545-1:2013, 'Railway applications. Fire protection on railway vehicles. Part 1: General', 2013.

19. TC Guide to thermocouple and resistance thermometry, Issue 6.0, TC Ltd., UK, 2004.

20. Kang, K. - "A smoke model and its application for smoke management in an underground mass transit station", Fire Safety Journal, 42, 2007, p. 218-231.

21. Rinne, T.; Hietaniemi, J.; Hostikka, S. - "Experimental Validation of the FDS Simulations of Smoke and Toxic Gas Concentrations", VTT Working Papers 66, 2007.

22. McGrattan, K., Floyd, J., Forney, G.P., Baum, H.R., Hostikka, S., "Improved radiation and combustion routines for a large eddy simulation fire model", Fire Safety Science, vol. 7, p 827-838. 2013.

23. Lázaro, D., Lázaro, M., Alvear, D., Jiménez, M.A., “Accuracy of the grid cell size for fire modelling in nuclear power plant scenarios", 24th International Conference on Structural Mechanics in Reactor Technology-SMiRT, Busan (Korea), 2017.

24. McGrattan, K., "Verification and Validation of Selected Fire Models for Nuclear Power Plant Applications". Volume 7. Fire Dynamics Simulator (FDS). NUREG1824. EPRI 1011999, 2007.

25. Nuclear Power Plant Fire Modeling Analysis Guidelines (NPP FIRE MAG). US Nuclear Regulatory Commission. NUREG-1934. 2012.

26. Transport Fire Safety Engineering in the European Union, Transfeu, Report WP6D6.2.1 Full scale test reports on passenger seats. FP7 Contract Number: 233786. 2012.

27. Alvear, D., Puente, E., Abreu, O., Peco, J., "Sensitivity Analysis of FDS 6 Results in Nuclear Plants", 14th International Seminar on Fire Safety in Nuclear Power Plants and Installations, Salford, United Kingdom, 2015.

28. Jahn, W., Rein, G., Torero, J.L., "The Effect of Model Parameters on the Simulation of Fire Dynamics". In Proceedings of the Ninth Symposium on Fire Safety Science, Karlsruhe, Germany, 2008. 
